\title{
ПЕДАГОГИЧЕСКИЕ УСЛОВИЯ ФОРМИРОВАНИЯ ПРАВОВОЙ ГОТОВНОСТИ БУДУЩИХ РЕМЕСЛЕННИКОВ К ПРОФЕССИОНАЛЬНОЙ ДЕЯТЕЛЬНОСТИ'
}

\section{PEDAGOGICAL CONDITIONS OF FORMATION OF LEGAL READINESS FOR FUTURE CRAFTSMEN TO PROFESSIONAL ACTIVITY}

\section{E. Bychkova}

Summary: The article presents the results obtained during the pedagogical study on the formation of the legal readiness of future craftsmen for professional activities through the design of the pedagogical process, taking into account the complex pedagogical conditions. The characteristic of pedagogical conditions is given and the main directions of their implementation are identified. The effectiveness of the application of pedagogical conditions for the formation of the legal readiness of future craftsmen for professional activities is justified: 1) the organization of the educational and legal environment that supports universally binding and professional legal attitudes and moral values; 2) integration of general, special and legal disciplines; 3 ) the use of active and productive methods of educational work; 4 ) legal self-education and self-development of students.

Keywords: craftsmen, readiness for professional activity, legal readiness of future craftsmen, pedagogical conditions, formation of legal readiness of future craftsmen for professional activity.
$\mathrm{H}$ аучно-техническое развитие и технологии промышленного производства обеспечили большой объем выпуска продукции массового потребления и перенасыщение товарного рынка изделиями стабильного качества. Политические и социально-экономические преобразования российского общества в конце XX века привели к дифференцированию спроса на потребительские товары и услуги и способствовали появлению новых работников на рынке труда, ориентированных на изготовление таких товаров и услуг. Работники, производящие товары и услуги по непосредственным заказам клиентов, называются ремесленниками, а их профессиональная деятельность - ремесленной [8].

Как форма хозяйственной деятельности ремесленничество существовало и развивалось в России до первой

\author{
Бычкова Екатерина Юрьевна \\ Соискатель, ФГАОУ ВО «Российский государственный \\ профессионально-педагогический университет», г. \\ Екатеринбург \\ bychkovakaterina@yandex.ru
}

Аннотация: В статье представлены результаты, полученные в ходе проведения педагогического исследования по формированию правовой готовности будущих ремесленников к профессиональной деятельности посредством проектирования педагогического процесса с учетом комплекса педагогических условий. Дана характеристика педагогических условий и выявлены основные направления их реализации. Обоснована эффективность применения педагогических условий формирования правовой готовности будущих ремесленников к профессиональной деятельности: 1) организация учебноправовой среды, поддерживающей общеобязательные и профессионально-правовые установки и морально-нравственные ценности; 2) интеграция общих, специальных и правовых дисциплин; 3) применение активных и продуктивных методов учебно-воспитательной работы; 4) правовое самообучение и саморазвитие обучающихся.

Ключевые слова: ремесленник, готовность к профессиональной деятельности, правовая готовность будущих ремесленников, педагогические условия, формирование правовой готовности будущих ремесленников к профессиональной деятельности.

трети XX века, но по идеологическим причинам искусственно было вытеснено из экономики нашей страны в последующие периоды. Возникшая в советский период система обучения индустриальных рабочих предполагала узкую специализацию, ограниченные самостоятельность, мобильность и ответственность, не предусматривала развитие коммуникативных, экономических и правовых навыков. Включенность работников в новые рыночные отношения приводит к необходимости подготовки работников принципиально нового типа - ремесленников. Современный ремесленник должен иметь опыт качественного выполнения индивидуальных заказов, обладать способностью к техническому творчеству, самостоятельностью для организации автономного производства и сбыта ремесленной продукции, социально-профессиональной мобильностью для адаптации 
к переменам, коммуникативностью для выстраивания социальных связей [8]. В условиях интеграции России в мировую экономику, развития рыночных отношений внутри страны и построения правового государства, усиливается необходимость формирования правовой готовности будущих ремесленников к профессиональной деятельности. Современный ремесленник должен ориентироваться на легальные формы осуществления своей деятельности, проявлять социальную ответственностью за результаты труда, иметь опыт защиты своих профессиональных прав и интересов с позиции законодательства и обычаев делового оборота.

В психолого-педагогической науке готовность к профессиональной деятельности рассматривается учеными как теоретическая и практическая проблема, выделяется большое количество форм и видов готовности: психологическая, профессиональная, педагогическая, нормативно-правовая и т.д. Например, Н. В. Кузьмина характеризует понятие «готовность к профессиональной деятельности» наличием у специалиста знаний, умений и навыков, позволяющих ему осуществлять свою деятельность на уровне современных требований науки и техники [5, с. 34]. Нормативно-правовая готовность рассматривается как «своевременно разработанная и изученная сотрудниками и военнослужащими совокупность законодательных и иных нормативных правовых актов, регулирующих (обеспечивающих) организацию деятельности органов и подразделений МВД России в особых условиях» [1]. С.А. Бондаренко определяет правовую готовность как «сложное психолого-педагогическое явление, сочетающее взаимосвязанные психологические особенности и нравственные качества личности, социально ценностные мотивы выбора профессии, способы поведения, специальные профессионально правовые знания, умения и навыки, обеспечивающие специалисту возможность трудиться в избранной им профессиональной сфере» [2].

Изучив различные точки зрения, встречающиеся в педагогической литературе, мы определили правовую готовность будущего ремесленника как «интегративное качество личности, основанное на правовых ценностях общества, отражающее его способность применять систему социально-правовых, профессионально-правовых, технолого-правовых, педагогико-правовых знаний и умений, опыт защиты и развития профессиональных прав и интересов, регулирования профессиональных отношений на основе законодательства и обычаев делового оборота» [9].

Формирование правовой готовности будущих ремесленников к профессиональной деятельности является целостным, последовательным, непрерывным процессом, требующим соблюдения комплекса педагогических условий. Педагогические условия - это «совокупность мер, направленных на повышение эффективности педагогической деятельности» [7]. Термин является общенаучным и широко используется в педагогических исследованиях. Например, А.Я. Найн определяет данное понятие как «совокупность объективных возможностей, содержания, форм, методов, средств и материальнопространственной среды, направленных на решение поставленных задач» [6, с. 44]. Н.М. Борытко рассматривает педагогические условия как «внешнее обстоятельство, оказывающее существенное влияние на протекание педагогического процесса, в той или иной мере сознательного сконструированного педагогом, предполагающего достижение определенного результата» [3]. Под педагогическими условиями мы понимаем совокупность организационно-педагогических, содержательно-педагогических и процессуально-педагогических условий, взаимовлияющих и взаимодополняющих друг друга.

Начальными положениями в разработке комплекса педагогических условий формирования правовой готовности будущих ремесленников к профессиональной деятельности являются: заказ государства, общества и личности в обеспечении качества профессионального образования; особенности профессиональной деятельности в условиях рыночной экономики; единство содержательных линий профессионального и образовательного стандартов и реализации принципов преемственности, последовательности, профессионально-правовой направленности в подготовке будущих ремесленников.

Мысчитаем, что успешному формированиюправовой готовности будущих ремесленников к профессиональной деятельности способствует соблюдение следующих педагогических условий: 1) организация учебно-правовой среды, поддерживающей общеобязательные и профессионально-правовые установки и морально-нравственные ценности; 2) интеграция общих, специальных и правовых дисциплин; 3) применение активных и продуктивных методов учебно-воспитательной работы; 4) правовое самообучение и саморазвитие обучающихся. Последовательно раскроем каждое условие.

Первое педагогическое условие - организация учебно-правовой среды, поддерживающей общеобязательные и профессионально-правовые установки и морально-нравственные ценности. Проблематично обучение студентов всем навыкам противостояния грубому эгоизму и манипуляциям в общении, но представляется возможным организация образовательной среды, в которой осуждаются и преодолеваются тенденции регрессивного развития. В образовательной среде всеми участниками учебно-воспитательного процесса должны признаваться и реализоваться нормы права, на основе которых формируется правомерное поведение. 
Представление ремесленной деятельности как своеобразного вида креативного предпринимательства приводит к необходимости усвоения обучающимися правовых норм, защищающих интересы частных лиц. На формирование и реализацию интересов частных лиц огромное влияние оказывают важнейшие формы общественного и индивидуального сознания - мораль и нравственность. Действия субъектов права в обязательном порядке подчиняются ряду нравственных норм, из которых клиентоориентированность, добросовестность, профессиональная честь характерны для развитой предпринимательской культуры. Частью общества одобряются и упрощенные нравы - необязательность, лукавство, сиюминутная выгода, которые могут быть более привлекательны для профессиональной деятельности. Юридические нормы, регулируя узкий круг социальных отношений, требуют от личности гораздо меньше, чем нравственный императив. Многообразие нравственных норм и сложность осуществления регулируемого ими оптимального выбора предопределяет создание образовательной среды требовательной ко всем субъектам образовательного процесса и ориентирующей на высокий уровень поведения, характерный для развитой предпринимательской культуры.

Bmoрое педагогическое условие - интеграция общих, специальных и правовых дисциплин. Профессиональная деятельность ремесленника связана с выполнением многих функций (управлением ремесленным предприятием, экономикой и финансами, технологией производства ремесленных работ, охраной труда и окружающей среды, реализацией готовой продукции, наставничеством), поэтому содержание правового обучения и воспитания должно соответствовать многофункциональной ремесленной деятельности. Поскольку в условиях минимального количества времени, отведенного на изучение правовых дисциплин и быстрого обновления содержания невозможно подробное изучение всех отраслей права, целесообразно выделять блоки правовых проблем, связанных с ремесленной деятельностью и рассматривать их как на общеобразовательных дисциплинах, так и на профессиональных, тем самым применяя на практике принцип профессионально-правовой направленности. Правовые проблемы необходимо соотносить с нравственным контекстом, разъясняя обучающимся соотношение понятий «мораль», «нравственность», «право», показывая место нормы в регуляции социальной жизни общества, т.е. реализовать сочетание правового обучения и правового воспитания. Комплексный подход достигается путем введения вопросов правовой направленности в содержание общих и специальных дисциплин, разъяснения обучающимся содержания понятий и правовых норм в контексте исторического и экономического развития страны.

Tретье педагогическое условие - применение актив- ных методов учебно-воспитательной работы, способствующих формированию правовой готовности будущих ремесленников к профессиональной деятельности: правовые разминки, интеллектуальные тренинги, правовые дебаты, семинары, деловые игры.

Например, правовые дебаты позволяют продемонстрировать обучающимися знания в области права и красноречие, подготовиться к участию в состязательных прениях сторон договора в обстановке максимально приближенной к реальной. В рамках дебатов обучающиеся отстаивают собственную точку зрения, аргументируют и доказывают правильность своей правовой позиции, демонстрируют тактику ведения переговоров. Проведение дебатов предполагает последовательное прохождение пяти этапов: 1) ориентация участников (постановка проблемы, формулирование цели исследования); 2) подготовка к проведению дебатов (исследование темы, сбор и анализ информации, построение линии утверждения и отрицания); 3) непосредственное проведение дебатов (выступление участников, анализ, вынесение решения); 4) обсуждение дебатов (фиксация личностных изменений обучающихся, выдача рекомендаций обучающимся с учетом обнаруженных у них личностных изменений, саморефлексия обучающихся); 5) практическое применение освоенного в деятельности. Использование данного метода предполагает активное взаимодействие участников образовательного процесса и способствует мотивации обучения, так как достигается личностная значимость учебного материала. Наличие состязательности стимулирует активную творческую деятельность, а также проработку изучаемого материала.

Активные формы обучения и воспитания развивают у обучающихся способность слушать собеседника, анализировать сказанное, формулировать вопросы, размышлять, критически перерабатывать информацию, делать осмысленные выводы. Кроме того, при реализации перечисленных методов обучения в педагогическом процессе, у обучающихся появляется возможность выступать в роли другой стороны, анализировать и понимать чужой опыт, оценивать собственные действия с позиции другого. Такие формы обучения и воспитания способствуют осознанному восприятию материала, формируют ценностное отношение к праву как регулятору профессиональной деятельности.

Четвертое педагогическое условие - правовое самообучение и саморазвитие обучающихся. Особая роль в процессе формирования правовой готовности будущих ремесленников к профессиональной деятельности отводится самостоятельной учебной работе, «во всех ее структурных компонентах: от постановки проблемы до осуществления контроля, самоконтроля и коррекции» [4]. В процессе формирования правовой готовности будущих ремесленников к профессиональной деятель- 
ности актуальными видами самостоятельной работы являются: накопление, структуризация и распространение правовой информации; решение практико-ориентированных правовых задач; исследовательская работа по выбранной теме; подготовка презентации.

В современных условиях знания аккумулируются в открытом информационном пространстве сети Интернет. Самым активным компонентом информационных систем, помимо технического и технологического, подразумевается человек. Поэтому актуализируются умения будущего ремесленника работать с компьютерными программами, справочными правовыми системами, интернет-сайтами предприятий, интернет-порталами бизнес-компаний, системами электронной коммерции и розничной торговли.

Другой причиной, актуализирующей самостоятельную работу для ремесленника, является малая численность работников ремесленного предприятия и отсутствие привязанности к структуре организации - все этапы профессиональной деятельности, от проекта ремесленного изделия до его реализации, ремесленник выполняет сам с небольшим количеством помощников. В условиях малочисленности работников и автономности существования актуализируются процессы информационной поддержки предприятия и принятия правового управленческого решения. Современная информационная инфраструктура позволяет оперативно получать достоверную информацию в области ремесленного законодательства, изучать нормативно-правовые документы предприятий ремесленного профиля, динамику продвижения ремесленных товаров и услуг на рынок, развивать навыки критического мышления, индукции и дедукции. На основе самостоятельного поиска необходимой информации, ее накопления, систематизации и критической оценки формируются актуальные знания, которые могут быть применены в последующей профессиональной ремесленной деятельности.

Применение практико-ориентированных правовых задач в учебном процессе, переход от простого к сложному, способствует развитию у обучающихся умений общеобязательного и профессионального правомерного поведения, освоению положительного опыта профессионального поведения и позитивной социальной направленности.

Исследовательская работа по выбранной теме поможет изучить положительные образы ремесленных предприятий, индивидуальных предпринимателей и самозанятых граждан, работающих в ремесленной сфере. Например, по интернет-сайту можно определить степень открытости субъектов малого бизнеса к сотрудничеству и кооперации, совместному сбыту продукции, возросшему влиянию потребителей, обслуживанию клиентов на более высоком уровне. Исследовательская работа позволяет выявить социальную направленность ремесленной деятельности и развивать профессионально значимые качества личности ремесленника: самостоятельность, умение дорабатывать инициированное дело до конца, представлять результаты своей деятельности, социальную ответственность.

Реализация предложенного комплекса взаимосвязанных педагогических условий проводилась в организациях среднего и дополнительного профессионального образования Свердловской области, реализующих экспериментальные программы подготовки будущих ремесленников. Было обновлено содержание учебных дисциплин, разработаны и внедрены в учебный процесс активные формы и методы организации педагогического процесса, спроектирована учебно-правовая среда, поддерживающая морально-нравственные ценности, активизировалась самостоятельная учебная работа обучающихся. На основании проведенного исследования можно констатировать, что реализация предложенного комплекса взаимосвязанных педагогических условий способствует формированию правовой готовности будущих ремесленников к профессиональной деятельности.

\section{ЛИТЕРАТУРА}

1. Громов М.А. Основные направления и виды обеспечения готовности сил и средств органов и подразделений МВД России к действиям при чрезвычайных обстоятельствах социально-политического и криминального характера / М.А. Громов, Э.Г. Федореев // Российский следователь. - 2012. - № 15. - С. 41-43.

2. Бондаренко С.А. Формирование профессиональной готовности конкурентоспособного специалиста / С.А. Бондаренко // Модернизация высшей школы: обеспечение качества профессионального образования: материалы Всерос. науч.-практ. конф. Барнаул, 22-23 окт. 2004 г. - Барнаул: Изд-во Алт. акад. экономики и права, 2004. - Ч. 1. - 188 с.

3. Борытко Н.М. В пространстве воспитательной деятельности: монография / Науч. ред. Н.К. Сергеев. - Волгоград: Перемена, 2001. - 181 с.

4. Коджаспирова Г.М. Педагогический словарь / Г.М. Коджаспирова, А.Ю. Коджаспиров. - Москва: Academia, 2000. - 176 с.

5. Кузьмина Н.В. Педагогическая психология: учебное пособие / Н.В. Кузьмина. - Санкт-Петербург: Изд-во В.А. Михайлова, 2008. - 209 с.

6. Найн А.Я. 0 методологическом аппарате диссертационных исследований /А.Я. Найн // Педагогика. - 1995. - № 5. - С. 44-49. 
7. Никитина Е.Ю. Теория и практика подготовки будущего учителя к управлению дифференциацией образования: дис. ... д-ра. пед. наук. - Челябинск, 2001. -427 c.

8. Romantsev G.M. Craft training in Russia: theory and practice of development / Romantsev G.M., Efanov A.V., Moiseev A.V., Bychkova E.Y., Karpova N.P., Tidemann B. // International Journal of Environmental and Science Education. - 2016. - V. 11. - № (14). - P. 7154-7165.

9. Romantsev G.M. Structural and Functional Model of Future Craftsmen Legal competence Generation during Professional Education / Romantsev, G.M., Efanov, A.V., Bychkova, E.Y., Moiseev, A.V. // International Journal of Environmental and Science Education. - 2016. - V. 11. - № (17). - P. 9787-9802.

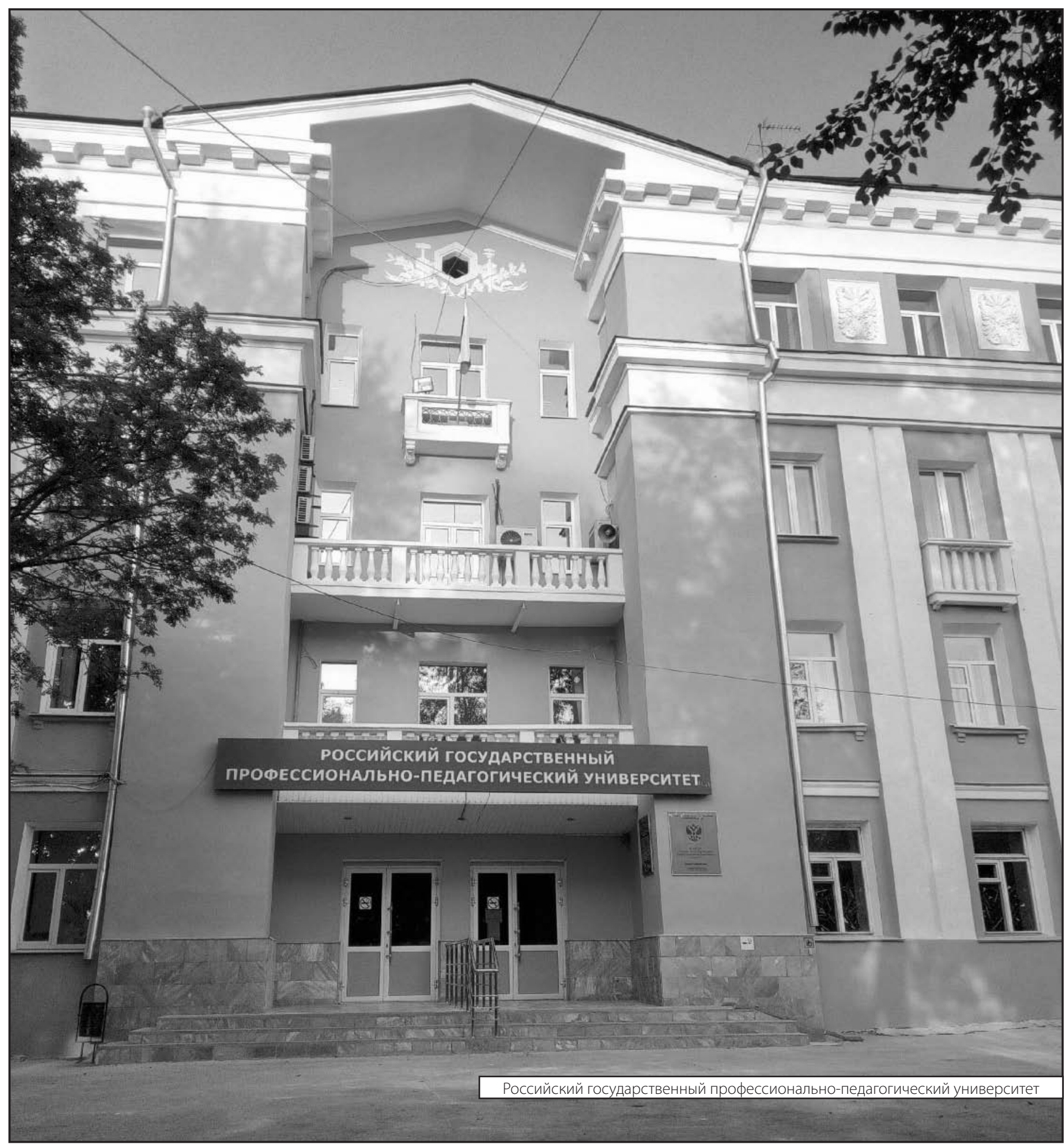

